\title{
O ensino da matemática nas escolas do campo por meio da Metodologia da Mediação Dialética
}

\section{Teaching mathematics in rural schools through the Dialectic Mediation Methodology}

\author{
Jaqueline Zdebski da Silva Cruz \\ Maria Lidia Sica Szymanski**
}

Resumo: Este artigo aborda a necessidade de um trabalho pedagógico dentro da modalidade Educação do Campo, especificamente no ensino da matemática. Busca justificar a defesa por um trabalho diferenciado, que tome como ponto de partida o conhecimento matemático do aluno e permita a sua ampliação de tal forma que os conhecimentos matemáticos adquiridos sejam realmente úteis em sua vivência de cidadão. A partir das Diretrizes Curriculares da Educação do Campo, este trabalho apresenta os pontos principais do desenvolvimento da Metodologia da Mediação Dialética, a qual possibilita estabelecer relações entre os diferentes saberes do aluno e do professor, de forma que o aluno possa superar seu conhecimento imediato sobre o mundo, pelos conhecimentos matemáticos historicamente construídos pelo homem.

Palavras-chave: Educação do Campo. Matemática. Metodologia da Mediação Dialética.

\begin{abstract}
This paper approaches the need for pedagogical work within the scope of Rural Education, mainly Mathematics teaching. It seeks to justify the defense of a differentiated work, which takes as its starting point, the students' mathematical knowledge and allows its broadening in such a way that the mathematical knowledge acquired is really useful in their everyday life. Taking the Rural Education Curricular Guidelines into account, this study presents the main points for the development of a dialectic mediation methodology, which establishes relations between the different knowledge of teachers and students, so that the students can overcome their immediate knowledge of the world, through mathematical knowledge historically built by humankind.
\end{abstract}

Keywords: Rural education. Mathematics. Dialectic Mediation Methodology.

\footnotetext{
* Mestranda do Programa de Pós-Graduação em Educação da Universidade Estadual do Oeste do Paraná. E-mail: <jaque_zdebski@hotmail.com>

** Professora da Universidade Estadual do Oeste do Paraná. E-mail: <szymanski_@hotmail.com>
} 


\section{Introdução}

Por muito tempo a educação camponesa foi trabalhada a partir de um currículo essencialmente urbano e, quase sempre, deslocada das necessidades e da realidade das pessoas que vivem neste contexto (PARANÁ, 2006). Apesar de terem ocorrido alguns avanços na legislação educacional ${ }^{1}$ nos últimos anos, as escolas para a população camponesa continuam, ainda hoje, encontrando as mais diversas dificuldades para implantar de forma eficaz, em sala de aula, um ensino que atenda às necessidades deste público alvo específico.

$\mathrm{Na}$ tentativa de superação do antigo modelo educacional, a Educação Rural, pela Educação do Campo, Calazans (1981) questiona a forma como ocorre o planejamento das políticas públicas nesta modalidade escolar:

Por que não se começa do "saber" que as populações demonstram possuir? Por que não se espera ouvir suas propostas utópicas, antes de rudemente esmagá-las com soluções pré-definidas? Por que não deixar que as propostas se expressem através de palavras do mundo das populações nos quais o sentido de vida, de preservação, de senso comum, têm raízes fincadas na terra? (CALAZANS, 1981, p. 189).

$\mathrm{Na}$ defesa de que a educação para os povos campesinos deva considerar suas especificidades e ser capaz de formar cidadãos críticos, reflete-se, neste artigo, sobre alguns aspectos da oferta educacional para os povos do campo no país, com o objetivo principal de justificar os motivos pelos quais esta parcela da sociedade necessita de um projeto educacional diferenciado que possa, ao contrário das propostas da Educação Rural, voltadas à formação de homens conformistas e aptos a dar continuidade ao projeto capitalista de desenvolvimento, oferecer um ensino de qualidade e que atenda às reais necessidades camponesas.

Nessa perspectiva, toma-se como base o trabalho específico com a matemática, objetivando que os conhecimentos matemáticos adquiridos pelo aluno camponês sejam realmente úteis em sua vivência de cidadão. Esse ensino deve valorizar o conhecimento do cotidiano do aluno não podendo se restringir apenas à reprodução de métodos, regras e técnicas preestabelecidas, como as que são muitas vezes apresentadas pelos livros didáticos e pelo ensino tradicional. $\mathrm{O}$ ensino da matemática nestas escolas precisa estar envolvido de valores, dos vínculos culturais e da riqueza de possibilidades para o trabalho com a matemática que a vida no campo pode oferecer.

\footnotetext{
${ }^{1}$ Entre as quais destacam-se, em caráter nacional, a Lei de Diretrizes e Bases da Educação Nacional n. 9394/96, as Diretrizes Operacionais para a Educação Básica nas escolas do campo de 2002, a Resolução no 2, de 28 de Abril de 2008, que estabelece as diretrizes complementares, e, em caráter estadual, a construção das Diretrizes Curriculares Estaduais da Educação do Campo em 2006.
} 
Como alternativa para um trabalho pedagógico significativo dentro da especificidade da Educação do Campo, que considere o conhecimento matemático trazido pelo aluno e permita sua ampliação, apresentam-se os pontos principais que embasam o desenvolvimento da Metodologia da Mediação Dialética (MMD), a qual possibilita satisfazer estes requisitos, estabelecendo relações entre os diferentes saberes dos alunos e do professor, de forma que o aluno possa superar seu conhecimento imediato sobre o mundo pelos conhecimentos matemáticos historicamente construídos pelo homem.

\section{O ensino para as populações camponesas no Brasil}

O ensino rural brasileiro iniciou-se de forma tardia, no século XX, e foi se desenvolvendo aos poucos com o objetivo de suprir as necessidades econômicas que iam surgindo no setor primário da economia com o crescimento da monocultura cafeeira, a qual necessitava de pessoas preparadas para fazer crescer sua produtividade, seus lucros e colocar em ação o projeto de desenvolvimento do país (CALAZANS, 1981).

Devido às dificuldades enfrentadas pelos camponeses com as mudanças provocadas desde o início da inserção do modo de produção capitalista no campo, aliadas à crescente industrialização das cidades, muitos abandonaram a vida no campo buscando novas oportunidades dentro das indústrias. Quando se atentou para os graves problemas decorrentes do êxodo rural, como o crescimento dos problemas sociais nas periferias e a diminuição do rendimento da terra pela falta de mão de obra, alguns movimentos buscaram barrar este processo. Uma das alternativas consideradas importantes seria a adaptação das escolas para o meio rural, pautando-as nas especificidades de seu povo, oferecendo-lhe subsídios para que se mantivesse em sua condição de população rural.

Porém estas preocupações de valorização até recentemente não estavam instituídas como políticas públicas. O programa oferecido ao povo do campo tornou-se um espaço onde se substituíam valores da sociedade agrária por valores da sociedade industrial, atendendo às demandas de modernização e industrialização do meio rural pela imposição da economia política (CESTILLE, 2009).

O modelo de escola pensado para o campo estava pautado nos valores da sociedade industrial, oferecido durante décadas, que visava construir um novo modo de vida no campo, influenciando ao máximo a diminuição da forma de produção baseada na agricultura de subsistência. Ao defender que o camponês precisaria conhecer e utilizar a produção com base no desenvolvimento científico, incentivando o uso de insumos, agrotóxicos, sementes e tecnologias, na verdade, esse projeto educacional queria que o camponês abandonasse a forma de produção que lhe proporcionava a subsistência e passasse a desenvolver a 
monocultura, pois, assim, ele teria que comprar os insumos, vender o excedente de sua produção e depender do mercado para comprar os demais componentes de sua alimentação através de terceiros, fazendo girar a lógica do capitalismo.

Portanto, o que realmente se objetivava com esse tipo de educação não seria a formação do camponês visando melhorar suas condições de vida, mas sim transformá-lo em um produtor, ainda que pequeno, consumidor de tecnologias e insumos agrícolas, promovendo a expansão das relações capitalistas de produção também no campo (CESTILLE, 2009).

O cenário político produzido a partir de 1980 contribuiu para que alguns setores da sociedade organizada, ligados aos movimentos sociais e à igreja, se interessassem de forma mais assídua pelas questões ligadas ao ensino para a população camponesa, provocando alterações significativas. Apesar de terem sido duramente reprimidos após o golpe militar, os movimentos nascidos nas décadas de 1950 e 1960 em sua maioria não se extinguiram e, juntamente com outros movimentos de contestação da ditadura militar, tanto do campo como urbanos, fizeram crescer a luta por uma educação que garantisse a aprendizagem dos conteúdos básicos historicamente produzidos pelos homens.

$\mathrm{Na}$ década de 1980, as lutas pela reforma agrária intensificaram-se. As manifestações dos trabalhadores do campo tiveram como principal estratégia a formação de acampamentos, organização que permitiu a formação de movimentos sociais $^{2}$, como o MST (Movimento dos Trabalhadores Rurais Sem-Terra), oficializado durante um encontro realizado em 1984 na cidade de Cascavel, no Paraná.

Depois que os movimentos sociais passaram a se interessar e agir colocando a questão educacional no terreno de seus direitos, na busca por uma educação de qualidade para os povos do campo, constituíram-se novos agentes, influenciando políticas que foram se alterando de maneira mais acelerada na busca por atender às novas demandas reivindicadas.

Entretanto, apesar dos esforços dos movimentos sociais, foi somente em 1996 que a Lei de Diretrizes e Bases 9.394 incluiu um artigo especificamente sobre as peculiaridades da vida no campo como princípio importante para a organização do processo escolar nesta modalidade. Este artigo deu base para os debates que já vinham sendo desenvolvidos na luta por uma Educação do Campo.

Art. 28. Na oferta da Educação Básica para a população rural, os sistemas de Ensino promoverão as adaptações necessárias à sua adequação às peculiaridades da vida rural e de cada região, especialmente:

\footnotetext{
${ }^{2}$ Outros movimentos sociais do campo também foram se organizando com o objetivo principal de luta pela reforma agrária, entre os quais podemos citar o Movimento dos Atingidos por Barragens (MAB), o Movimento dos Pequenos Agricultores (MPA) e o Movimento das Mulheres Camponesas (MMC), que passaram a lutar por outras necessidades relacionadas à sua causa principal, a reforma agrária, transformando-se também em agentes no projeto de Educação do Campo pensado neste período.
} 
I- conteúdos curriculares e metodologias apropriadas às reais necessidades e interesses dos alunos na zona rural;

II- organização escolar própria, incluindo adequação do calendário escolar às fases do ciclo agrícola e às condições climáticas;

III- adequação à natureza do trabalho na zona rural. (BRASIL, 1996).

Ainda que a Lei 9.394 tenha reconhecido a especificidade da população campesina e indicado formas de atendê-la, as dificuldades para implementá-las metodologicamente nas redes de ensino permaneceram (MENDES, 2009). Estas dificuldades foram sendo superadas pela dedicação dos próprios movimentos sociais ao desenvolvimento e socialização de suas práticas educativas e pelo empenho dos órgãos educacionais voltados à Educação do Campo que passaram a se organizar pautados em concepções diferenciadas daquelas que vinham direcionando as políticas públicas para esta área específica até então.

O MST, enquanto movimento social, foi se constituindo como um dos principais agentes na luta pela educação camponesa, cumprindo importante papel dentro da proposição de conhecimentos/teorias por meio de conceitos e modelos desenvolvidos na prática sobre a escola e a educação para os trabalhadores do campo. Portanto, é fundamental conhecer minimamente qual o sentido educativo presente nas práticas do movimento para a compreensão das concepções pedagógicas que as embasam.

Desde as primeiras discussões sobre educação dentro do MST, uma certeza sempre esteve presente: a educação que se buscava construir deveria ser diferente daquela educação repassada pela Escola Rural, mantida pelo Estado e frequentada por grande parte dos militantes. A escola pensada para os camponeses deveria ser tal que "conseguisse criar antídotos contra a inércia, a acomodação, a morosidade, a burocracia, a submissão" (SAVELI, 2000, p. 22), que vinham sendo pregadas explícita ou implicitamente pela Educação Rural, e deveria pautar-se na realidade vivida pelo camponês, a fim de oferecer-lhe os conhecimentos e as experiências concretas, necessárias para superá-la (D’AGOSTINI, 2009).

Para o MST, a educação deve ser considerada como uma experiência mais ampla do que aquela habitualmente atribuída à escolarização formal, melhor representada através da denominação "formação humana", processo que inclui a educação escolar, apenas como mais um dos tempos e espaços de formação. Com esta concepção educacional, o MST utiliza o trabalho, a luta e sua própria cultura como eixos de formação dentro de sua proposta, com o objetivo de fazer crescer a consciência social, política e de classe de seus membros. Assim, o movimento entende que é papel da educação escolar, de forma mais específica, da escola: 
[...] interpretar esses processos educativos que acontecem fora, fazer uma síntese, organizar esses processos educativos em um projeto pedagógico, organizar o conhecimento, socializar o saber e a cultura historicamente produzidos, dar instrumentos científicos técnicos para interpretar e intervir na realidade, na produção e na sociedade. (ARROYO, 1999, p. 27).

Para o MST a escola deve desenvolver-se em torno de alguns princípios relacionados aos seus objetivos, entre os quais: educar para transformar; educar a partir da prática, do trabalho; educar a partir da realidade; educar com autonomia do aluno; formar sujeitos históricos; formar o indivíduo como um todo; e ensinar a real história e a real situação da pessoa (MST, 2012). Estes princípios e sua vivência foram uma das principais influências nos debates para o desenvolvimento de políticas públicas voltadas à Educação do Campo.

A luta educacional travada pelos movimentos sociais do campo resultou em conquistas importantes, entre as quais a aprovação, em 2001, do Plano Nacional de Educação através da Lei 10.172, que entre outros aspectos prevê formas de organização mais flexíveis para as escolas do campo, a realização da formação de professores de forma condizente com as necessidades campesinas assim como a criação de órgãos, políticas e ações voltadas ao tema no âmbito dos estados (CESTILLE, 2009).

Entre as conquistas está a aprovação das Diretrizes Operacionais para a Educação Básica nas Escolas do Campo, em 2002, considerada o principal avanço para esses sujeitos sociais, tanto pelo seu conteúdo quanto pela forma como foi construída e por seus objetivos:

Estas Diretrizes, com base na legislação educacional, constituem um conjunto de princípios e de procedimentos que visam adequar o projeto institucional das escolas do campo às Diretrizes Curriculares Nacionais para a Educação Infantil, o Ensino Fundamental e Médio, a Educação de Jovens e Adultos, a Educação Especial, a Educação Indígena, a Educação Profissional de Nível Técnico e a Formação de Professores em Nível Médio na modalidade Normal. (BRASIL, 2002, p. 37).

Aprovada em 2008 pela Câmara de Educação Básica do Conselho Nacional de Educação, a Resolução n. 2 de 28 de abril complementa a legislação nacional da Educação do Campo determinando diretrizes, normas e princípios para o desenvolvimento de políticas públicas específicas para esta modalidade de ensino. Esta resolução trata, entre outros pontos, da necessidade de se respeitar a identidade e a cultura do camponês dentro do processo educativo. De acordo com o seu artigo sétimo:

$\int 1^{\circ}$ A organização e o funcionamento das escolas do campo respeitarão as diferenças entre as populações atendidas quanto à sua atividade econômica, seu estilo de vida, sua cultura e suas tradições. 
$\int 2^{\circ} \mathrm{A}$ admissão e a formação inicial e continuada dos professores e do pessoal de magistério de apoio ao trabalho docente deverão considerar sempre a formação pedagógica apropriada à Educação do Campo e às oportunidades de atualização e aperfeiçoamento com os profissionais comprometidos com suas especificidades (BRASIL, 2008, p. 3).

Pode-se perceber, através das modificações apresentadas anteriormente, que as políticas educacionais continuam recebendo alterações de acordo com os interesses de determinadas classes. A diferença nítida que pode ser identificada a partir da década de 1980/1990 é que alguns setores interessados na questão educacional do campo modificaram sua forma de atuação: deixaram o conformismo de lado e, com base sólida constituída nos movimentos sociais do campo, transformaram-se em agentes ativos na luta pela garantia dos direitos adquiridos.

O crescimento da força exercida pelos movimentos sociais do campo reflete sua auto-organização e a importância das parcerias firmadas com as demais entidades interessadas pela causa, como universidades, educadores, núcleos regionais de educação e organizações não governamentais, que ajudaram e ajudam, no sentido de oferecer subsídios teóricos e práticos para o estudo, planejamento e organização das ações.

No Paraná, as conquistas alcançadas por meio da luta conduzida pelos movimentos sociais do campo foram traduzidas na construção das Diretrizes Curriculares da Educação do Campo no ano de 2006, documento considerado como o principal avanço nas políticas educacionais para esta área, o qual será alvo de análise no próximo tópico.

\section{Diretrizes Curriculares da Educação do Campo}

A construção das Diretrizes Curriculares da Educação do Campo no Paraná, em 2006, foi mais um passo importante na afirmação da educação como um direito universal. Sua constituição se deu de forma horizontal, recebendo participação dos movimentos sociais, universidades, setores educacionais do Estado e dos professores da rede estadual de ensino. Este documento é o orientador do currículo para toda a rede pública estadual de ensino e defende a necessidade de um trabalho pedagógico específico para o desenvolvimento das disciplinas nesta modalidade educacional (PARANÁ, 2006).

As concepções implícitas no texto tangenciam a concepção de mundo, de educação e de escola advindas das experiências educativas do MST, anteriormente pontuadas no texto. Isso não acontece por acaso, mas devido à participação ativa deste movimento na proposição de políticas educacionais e pelas parcerias realizadas entre movimentos sociais e órgãos educacionais. Somente a título de exemplificação, citamos parte do documento das diretrizes que discorre sobre 
os espaços educativos e que, a exemplo do movimento, não vê a escola como espaço único de aprendizagem:

A escola é o lugar das relações educativas formais. O mundo atual, porém, exige que na escola sejam valorizados lugares em que acontece a educação, na sua vertente informal e não-formal. A roça, a mata, os rios ou o mar, as associações comunitárias etc. são lugares educativos que, às vezes, justamente por causa do contato diário, passam despercebidos, esquecidos no momento da elaboração dos planejamentos de ensino (PARANÁ, 2006, p. 49).

O reconhecimento da defasagem educacional historicamente sofrida por estas populações e o entendimento de que as concepções que embasaram as políticas até então deveriam ser repensadas, refletem-se no texto das diretrizes em diversos momentos, principalmente quando ele explicita seus objetivos: "Uma das proposições deste documento é desenvolver uma cultura de 'indagações' que leve à superação do modo tradicional, autoritário e enciclopédico do fazer pedagógico" (PARANÁ, 2006, p. 47).

As Diretrizes para a Educação do Campo afirmam que "Os sujeitos do campo têm direito a uma educação pensada, desde o seu lugar e com a sua participação, vinculada à sua cultura e às suas necessidades humanas e sociais" (PARANÁ, 2006, p. 9) e deixam claro que a educação que se quer construir e oferecer para o camponês paranaense deve ser formadora de cidadãos críticos, diferentemente daquela até então existente:

Busca-se uma educação que seja crítica, cuja característica central é a problematização dos conhecimentos. Problematizar implica discutir os conteúdos de forma a gerar indagações e não de forma enciclopédica e mecânica. Para tanto, na educação do campo, o tema questão agrária é essencial para compreender os determinantes que levaram a educação do campo a estar historicamente marginalizada nas políticas educacionais (PARANÁ, 2006, p. 30).

O texto das diretrizes apresenta as características diferenciadas que se objetivam construir nas escolas do campo no estado e estão ligadas à concepção de escola como "local de apropriação de conhecimentos científicos construídos historicamente pela humanidade e local de produção de conhecimentos em relações que se dão entre o mundo da ciência e o mundo da vida cotidiana" (PARANÁ, 2006, p. 29). E, sendo assim,

[...] a escola deve realizar uma interpretação da realidade que considere as relações mediadas pelo trabalho no campo, como produção material e cultural da existência humana. A partir dessa perspectiva, deve construir conhecimentos que promovam novas relações de trabalho e de vida para os povos no e do campo (PARANÁ, 2006, p. 32). 
Para tanto, no desenvolvimento do trabalho pedagógico, torna-se fundamental considerar a cultura dos povos do campo em sua dimensão empírica articulada à perspectiva teórica e fortalecer a educação escolar como processo de apropriação e elaboração de novos conhecimentos, fazendo emergir conteúdos e debates, entre outros, sobre a diversificação de produtos relativos à agricultura e o uso de recursos naturais, a agroecologia e o uso das sementes crioulas, a questão agrária e as demandas históricas por reforma agrária, os trabalhadores assalariados rurais e suas aspirações por melhores condições de trabalho, a pesca ecologicamente sustentável e o preparo do solo.

Com base nesta necessidade de trabalho com alguns temas principais, o texto das diretrizes apresenta os eixos temáticos, ou seja, temas que são entendidos como centrais e que devem ser focalizados nos conteúdos escolares com o intuito de "motivar e enriquecer o debate nas escolas do campo, ampliar as proposições pedagógicas, propiciar um repensar das aulas, da prática social dos professores, dos alunos e da comunidade escolar" (PARANÁ, 2006, p. 34). Os eixos apontados no texto são: trabalho - divisão social e territorial; cultura e identidade; interdependência campo-cidade, questão agrária e desenvolvimento sustentável; organização política, movimentos sociais e cidadania.

O texto das diretrizes também sugere possíveis encaminhamentos metodológicos que se referem "à valorização do ser humano que está diretamente no ambiente da sala de aula; à valorização dos saberes da experiência; a uma educação que supere a dimensão apenas enciclopédica e valorize a prática social dos envolvidos no ato pedagógico" (PARANÁ, 2006, p. 35) dentro de cada área específica.

Para que possa haver essa valorização, as diretrizes propõem como estratégia a articulação dos conhecimentos sistematizados com a realidade do aluno. A realização efetiva desta articulação requer esforço por parte de professores e equipes pedagógicas no sentido de refletirem sobre que conteúdos culturais dos povos do campo devem estar presentes nas disciplinas para que instrumentalizem os alunos a compreenderem o mundo em que vivem e quais são os saberes dos povos do campo que precisam integrar os currículos das disciplinas. (PARANÁ, 2006).

As respostas para estas e outras perguntas que nascem no planejamento e desenvolvimento das disciplinas, segundo as diretrizes, só serão encontradas através da realização de investigação, por parte dos professores e da equipe pedagógica, quanto às especificidades do contexto do qual estes alunos fazem parte.

Ao analisarmos a forma como deve ocorrer o ensino para torná-lo realmente significativo na formação campesina, podemos perceber a importância atribuída ao trabalho docente. $\mathrm{O}$ professor que pretenda engajar-se seriamente 
neste trabalho necessita de estudos e realização de constantes pesquisas. Precisa rever suas concepções e estar empenhado no difícil planejamento de aulas que possam valorizar as indagações dos alunos, a fim de lhes possibilitar o questionamento da vida.

Segundo as diretrizes, é preciso que o professor seja um inquiridor nas aulas e, o mais importante, que "o professor planeje o que será pesquisado, para que os alunos não fiquem na mera descrição dos acontecimentos dos quais participam todos os dias" (PARANÁ, 2006, p. 48).

A criação de disciplinas específicas sobre temas importantes ligados à vida do campo assim como o trabalho interdisciplinar realizado através do tema gerador podem ser alternativas interessantes para fazer emergir o debate e o interesse dos alunos para os eixos temáticos.

Apesar de sugerir algumas possíveis metodologias, as diretrizes enfatizam que "A organização dos saberes escolares pode seguir diferentes encaminhamentos metodológicos, desde que haja clareza de qual é a concepção de educação do campo que se quer desenvolver" (PARANÁ, 2006, p. 49). Nessa perspectiva, a seguir, apresenta-se a Metodologia da Mediação Dialética, como alternativa metodológica para o trabalho com a matemática nas escolas do campo.

\section{O ensino da matemática nas escolas do campo e a Metodologia da Mediação Dialética}

A importância atribuída ao ensino da matemática está vinculada ao papel decisivo que ela desempenha enquanto área do conhecimento, permitindo resolver problemas da vida cotidiana e funcionando como instrumento essencial para a construção de conhecimentos em outras áreas.

Ao adquirir competências matemáticas o estudante poderá, dentre outras coisas: compreender, descrever e representar de forma organizada o mundo que o cerca; analisar a interdependência entre grandezas e expressá-las algebricamente; construir procedimentos para coletar, organizar e comunicar dados, utilizando tabelas, gráficos e representações que aparecem no seu dia a dia; conhecer e interpretar os números, compreender o sistema numérico e lidar com problemas diversos que envolvem raciocínio matemático no dia a dia (BRASIL, 1997).

Considerando a necessidade da utilização de conhecimentos matemáticos para o desenvolvimento de diversas atividades no dia a dia da vida no campo, o trabalho com esta disciplina em sala de aula deve capacitar o aluno a, ao se deparar com estas diversas situações, utilizar o conhecimento adquirido da melhor forma possível para solucionar seu problema. 
Entretanto, o conhecimento escolar assimilado pelo aluno somente será capaz de dar conta destas suas necessidades se o aluno conseguir fazer a relação entre o conhecimento escolar e o problema cotidiano a ser solucionado, e isso, por sua vez, somente será possível se a metodologia de ensino utilizada em sala de aula for tal que articule os conteúdos sistematizados com a realidade campesina através do trabalho com questões relacionadas ao cotidiano do campo, como: noções de quantidade relacionadas à produção, aos gastos e lucros; medidas geométricas relacionadas ao tamanho de terras e edificações; o desenvolvimento do raciocínio lógico face aos problemas enfrentados pelo camponês no seu dia a dia, a fim de facilitar o seu trabalho no campo.

Proporcionar ao aluno condições para que ele consiga fazer essa relação entre conhecimento sistematizado e seu cotidiano possibilita-lhe, gradativamente, adquirir independência, aprendendo a fazer por si só estas relações.

As Diretrizes Curriculares da Educação do Campo colocam que o ensino realizado de maneira interdisciplinar pode ser um dos caminhos para superar o trabalho pedagógico fragmentado e permitir ao aluno associar mais facilmente o conhecimento escolar às aplicações de sua vivência, superando a forma mecânica e divorciada da realidade com que muitas vezes é trabalhado o ensino da matemática. Entretanto, a postura docente frente ao processo de aquisição do conhecimento e com base em sua concepção de mundo, de sujeito e das relações sociais de produção é que possibilitará o fio condutor do trabalho pedagógico.

Segundo essas mesmas diretrizes, entre as características da educação do campo que se pretende construir, está a forma de organização e seleção dos conteúdos a serem trabalhados:

[...] conteúdos escolares são selecionados a partir do significado que têm para determinada comunidade escolar. Tal seleção requer procedimentos de investigação por parte do professor, de forma que possa determinar quais conteúdos contribuem nos diversos momentos pedagógicos para a ampliação dos conhecimentos dos educandos. Estratégias metodológicas dialógicas, nas quais a indagação seja freqüente, exigem do professor muito estudo, preparo das aulas e possibilitam relacionar os conteúdos científicos aos do mundo da vida que os educandos trazem para a sala de aula (PARANÁ, 2006, p. 28).

Assim o ensino da matemática em escolas do campo precisa estar envolvido de valores, vínculos culturais e conhecimentos do cotidiano do aluno, que são partes integrantes dos recursos desenvolvidos e aproveitados na construção do conhecimento científico (MONTEIRO; LEITÃO; ASSEKER, 2009).

Apesar da existência de uma gama de opções metodológicas a serem usadas para a condução do processo de ensino-aprendizagem, o fator que possibilitará ao professor a delimitação de seu norte é sua visão de mundo e sua 
concepção de sujeito e de educação. É fundamental que os professores, ao desenvolverem seu trabalho em sala de aula, conheçam estratégias metodológicas diferenciadas, como a investigação matemática, a história da matemática, a resolução de problemas, a etnomatemática, entre outras, e saibam utilizar elementos destas metodologias, encaixando-as em seu planejamento mais amplo de tal forma que elas contribuam para o processo de aprendizagem, buscando que todos os alunos tenham a possibilidade de apropriar-se dos conhecimentos matemáticos essenciais para a construção de sua cidadania.

Dentre estas possíveis metodologias a serem aplicadas, destaca-se uma concepção metodológica ampla e recente, a Metodologia da Mediação Dialética (MMD), que considera, além do saber cotidiano do aluno, o seu desenvolvimento como ser histórico e social, superando as abordagens pedagógicas mecânicas, descontextualizadas, frequentemente encontradas nas salas de aula, podendo proporcionar o desenvolvimento de um ensino matemático significativo para o aluno por operacionalizar o método dialético na sala de aula.

A MMD é uma metodologia baseada nas concepções da teoria marxista, centrada nos processos de ensino (desenvolvido pelo professor), de aprendizagem (desenvolvido pelo aluno) e principalmente na relação entre ambos. Tem como eixo central a mediação pedagógica, a relação dialética que se estabelece entre professor e aluno, entendidos como seres sociais que desenvolvem a aula e, nela, se desenvolvem.

Nesta metodologia, o plano do imediato, considerado como sendo aquele constituído pelos saberes já aprendidos pelo aluno ou de seu senso comum, é o ponto de partida para a compreensão da totalidade pretendida, o plano do mediato, que é constituído pelo saber cientificamente aceito.

Para Arnoni (2011, p. 9), a mediação é “a relação de tensão (contradição), a força negativa que une o imediato ao mediato e, por isso, também os separa e os distingue". Segundo a mesma autora, a dialética é "a lógica do movimento, da evolução, da mudança e, portanto considera as coisas e os conceitos no seu encadeamento e nas suas relações mútuas, em ação recíproca" (ARNONI, 2011, p. 6).

Planejar uma aula, de acordo com a perspectiva dialética, exige concebê-la como uma práxis educativa, processo intencional e sistemático, através do qual se trabalha o saber cultural produzido historicamente, o que é um desafio para o professor, à medida que dele requer uma mudança conceitual e postural, já que nesta perspectiva a aula é uma totalidade processual, dinâmica e complexa, formada por relações contraditórias que devem ser muito bem estudadas com o intuito de serem compreendidas sob a perspectiva dialética (ARNONI; OLIVEIRA; ALMEIDA, 2007). 
O desenvolvimento de uma aula, nesta perspectiva, impõe que o professor considere o saber imediato do aluno, ou seja, o conhecimento que ele traz, valorizando-o e relacionando-o com o conhecimento científico, correspondente ao mediato pretendido que o aluno adquira, para que ele consiga estabelecer relações entre estes conhecimentos, evitando a fragmentação decorrente do aprender "o que cai na prova”, isto é, o "conhecimento do professor", necessário para a resolução da prova.

O desenvolvimento desta metodologia em sala de aula, por ser dialético, ocorre de forma integrada; entretanto, por fins didáticos, ela se apresenta através de etapas que relacionam-se entre si e com o todo e denominam-se Resgatando, Problematizando, Sistematizando e Produzindo, e que serão mais adiante brevemente definidas.

A título de exemplo podemos refletir sobre uma aula sobre geometria de acordo com essa metodologia. Suponhamos que se pretenda trabalhar com a determinação da área de um triângulo.

Iniciamos nossa aula pelo primeiro dos quatro momentos desta metodologia que é o Resgatando. Neste momento, o professor deve buscar resgatar o conhecimento imediato do aluno sobre o assunto a ser ensinado. Essa busca permite identificar os possíveis erros nas concepções dos alunos e permite que o professor determine um ponto de partida para a aula que seja comum a ele e aos alunos. Nesta fase, o professor deve comparar o conhecimento mediato que ele pretende que os alunos se apropriem com o saber imediato do aluno, constituído pelos conhecimentos que o aluno já traz, buscando as contradições que se estabelecem entre eles para transformá-las em problematização para uma situação de ensino (ARNONI; OLIVEIRA; ALMEIDA, 2007).

O Resgatando, por ser o momento inicial da aula, deve ser dedicado de forma exclusiva ao aluno. O professor, ao apresentar um triângulo e solicitar que os alunos determinem ou que explicitem como eles fariam para determinar sua área, deve abrir espaço para que todos exponham sua forma de resolver o problema. Para que estes alunos consigam expressar o conhecimento imediato, é extremamente importante que lhes seja oferecida abertura para a utilização de diferentes formas de expressão, como a linguagem verbal, o desenho, o recorte, a dobradura, entre outros, realizando manipulações e resgatando os conhecimentos que eles já possuem sobre essa figura geométrica.

O professor pode ainda pedir que os alunos construam outros triângulos, diferentes daquele por ele apresentado, de tal forma que saibam calcular a área destes novos triângulos. Ele também pode solicitar que os alunos acrescentem informações e medidas adicionais em seus triângulos ou que relacionem a figura 
com objetos de seu dia a dia para que a determinação da área seja possível de ser realizada através dos conhecimentos que os alunos dispõem.

Como estes alunos possuem a especificidade de serem do campo, o professor pode lhes solicitar que relacionem o problema de calcular a área de um triângulo com problemas enfrentados no cotidiano da vida campesina e que envolvam a determinação de áreas de terras com formato de triângulos, cálculos de áreas de partes de construções que possuam esta mesma forma ou outras situações em que exista a necessidade do cálculo da área de um triângulo. Solicitar que cada aluno faça uma pesquisa com seus familiares e vizinhos sobre como realizam estas medições de forma prática também contribui para que o aluno saiba melhor explicar a estratégia de resolução por ele adotada.

Ao pesquisar como os familiares realizam o cálculo de áreas com formatos triangulares, o aluno pode relatar a utilização de aproximações, o que é muito comum no cotidiano campesino. Muitas vezes ao desejar saber, por exemplo, a média de produção ou de lucro em determinada área, é muito mais cômodo que o camponês realize aproximações do que uma medição exata, a qual, além de muito mais difícil, pode ser desnecessária. Essa aproximação pode ser feita, por exemplo, dividindo o espaço territorial triangular em partes menores, de forma quadrada, cuja área pode ser calculada mais facilmente. A junção das áreas dos vários quadrados resulta numa área aproximada, o que é suficientemente satisfatório para atender às necessidades que justificaram a determinação desta área.

Ao coletar os dados produzidos pelos alunos, o professor encontrará subsídios para dar continuidade ao tema "Área de triângulos". Durante a análise das representações produzidas, ele conseguirá identificar quais são os conhecimentos que o aluno possui sobre triângulos e sobre cálculo de áreas triangulares. Da mesma forma, poderá perceber quais são as principais dificuldades e erros cometidos pelos alunos, o que lhe permitirá comparar e buscar as contradições existentes entre esse conhecimento imediato com o conhecimento mediato por ele pretendido.

Um segundo momento é chamado de Problematizando. Segundo Arnoni; Oliveira e Almeida (2007), neste momento o desafio que o professor deve superar é o de colocar o aluno em uma situação desafiadora, fazer com que ele perceba as contradições existentes entre o seu conhecimento imediato e o conhecimento apresentado pelo professor, estimulando o aluno a buscar soluções e a identificar a insuficiência dos seus saberes iniciais. Isso acontece no momento em que, nas trocas verbais com o professor, os alunos são convocados a argumentar em favor das suas ideias.

Durante o Problematizando, mais uma vez o professor possui o papel de orientador do processo e deve propiciar um ambiente de discussão, uma situação 
desafiadora, na qual os alunos possam identificar as deficiências dos seus modelos de solução para o problema e buscar outras melhores. Novamente, a título de exemplo, podemos imaginar o caso de um aluno que tenha exibido uma forma inusitada cientificamente de determinação da área do triângulo, cujo modelo, suponhamos, tenha servido para determinar a área de um triângulo específico por ele construído. Neste caso o professor pode solicitar que toda a turma utilize o modelo do colega aplicando-o a outros triângulos, buscando descobrir por que ele funciona somente para o caso específico, instigando desta forma situações nas quais estes alunos possam, ao encontrar regularidades, chegar a uma forma de cálculo mais genérica, como a que se pensa a área do triângulo utilizando sua base e altura como elementos constituintes de um retângulo, cuja área pode ser mais facilmente calculada ${ }^{3}$.

Ressalte-se que esta fase não pode ser apresentada ao aluno de forma muito facilitada ou dificultada, pois pode tornar-se desestimulante. Importante é que o professor tome o cuidado de alertar seus alunos no sentido de que apontar limitações ou erros conceituais na solução por eles encontrada não tem o objetivo de ridicularizá-los ou rebaixá-los, mas faz parte do processo de construção de novos conhecimentos.

A terceira etapa da aula, Sistematizando, não pode ser isolada de forma prática das demais, caso contrário estar-se-ia rompendo com a almejada unidade entre teoria e prática. Nesta fase, o professor deve desenvolver uma situação que permita ao aluno compreender as relações entre os saberes mediato e imediato, organizando suas ideias de forma a sanar aquele desconforto conceitual causado pela problematização. O professor deve retomar e discutir as questões levantadas como problemas, possibilitando ao aluno compreendê-las e não somente memorizá-las (ARNONI; OLIVEIRA; ALMEIDA, 2007).

Neste "momento", o professor retoma e discute as questões-problema com a sala, trabalhando as informações científicas do conceito estudado e propiciando ao aluno a compreensão delas, e não apenas sua memorização. Portanto, não se trata de o professor, simplesmente, declamar o conceito científico, lê-lo no texto didático ou escrevê-lo na lousa, e sim de estabelecer uma conversação sobre o saber científico que "resolve" a problematização, para que o aluno possa superar a contradição a ela (problematização) inerente (ARNONI; OLIVEIRA; ALMEIDA, 2007, p. 155-156).

\footnotetext{
${ }^{3}$ A fórmula de que trata o texto pode ser demonstrada e facilmente compreendida pelos alunos através de uma manipulação geométrica do triângulo. Essa fórmula da área do triângulo (A) com base de medida $b$ e altura medindo $b$ pode ser expressa matematicamente por: $A=\frac{b \times h}{2}$
} 
Aqui o importante é que a voz principal seja a do professor, que, ciente de algumas das dificuldades de seus alunos, pode reorganizar e abordar todos os conceitos envolvidos com a definição do triângulo e de sua área, assim como retomar questões problema apresentadas pelos alunos, permitindo-lhes compreender as relações existentes entre o seu conhecimento imediato e o conhecimento mediato organizado de forma sistematizada.

Apesar de ter como principal agente o professor, este momento também é importante para que os alunos possam sanar as dúvidas remanescentes e questionar sobre o que ainda não ficou esclarecido a contento. Desta forma, percebe-se que mesmo nesta etapa o aluno possui papel ativo na elaboração das novas sínteses.

O ponto de chegada da metodologia apresentada é o Produzindo, momento em que o aluno deve expressar da forma que achar mais clara as sínteses cognitivas elaboradas durante o processo de aprendizagem (ARNONI; OLIVEIRA; ALMEIDA, 2007). É quando o professor pode solicitar que o aluno volte ao problema inicial e o solucione utilizando o conhecimento adquirido na aula. Pode também pedir que este aluno apresente situações relacionadas ao seu cotidiano e que sejam possíveis de se resolverem através da utilização deste conhecimento - exercício que pode ser resolvido em conjunto pela turma e serve para incentivar a construção, pelo aluno, de relações entre o saber sistematizado em sala e suas vivências diárias.

Um trabalho de pesquisa realizado pelo professor sobre a cultura, os costumes e o cotidiano de seus alunos lhe permitirá obter subsídios para, ele mesmo, propor problemas instigantes, relacionados à vivência do aluno, que podem ser resolvidos através da aplicação dos conhecimentos adquiridos na aula. A realização de pesquisas é parte fundamental de um trabalho pedagógico bem sucedido, conforme apontam as diretrizes estaduais:

Em se tratando da educação do campo, a pesquisa é essencial para que se desvelem as relações sociais de produção, os saberes que estão presentes no cotidiano do trabalho, da organização política, da negociação econômica dos produtos. Ao descobrir os saberes da vida cotidiana, o professor terá mais elementos para construir planejamentos de ensino, selecionar textos para estudo, organizar a aula, o processo pedagógico (PARANÁ, 2006, p. 48).

Através das sínteses apresentadas pelos alunos nesta última etapa, o professor pode avaliar todo o processo e, caso seja necessário, retomará pontos que não foram completamente esclarecidos durante a realização das etapas anteriores.

Segundo Arnoni; Oliveira e Almeida (2007, p. 143), “a mediação permite que o imediato seja superado no mediato, sem, no entanto, que o primeiro seja anulado ou suprimido pelo segundo; ao contrário, o imediato está presente no 
mediato", ou seja, pela superação do conhecimento inicial chega-se ao conhecimento crítico e dialético, que não supõe a extinção do conhecimento imediato e que se constitui em um novo ponto de partida, um novo saber imediato.

Sabe-se que, quando se ensina matemática ou outra ciência, existem pelo menos duas possibilidades de processos possíveis de estarem ocorrendo na mente do aluno: ele pode assimilar o conhecimento científico apresentado pelo professor e abandonar completamente a ideia do senso comum que tinha sobre determinado assunto - mudança conceitual -, ou pode conviver com as duas explicações ao mesmo tempo, aquela apresentada pelo professor e a explicação própria que ele já havia formulado anteriormente - perfil conceitual. (MORTIMER, 2011).

Como os conhecimentos imediatos dos alunos são fortemente influenciados por suas diferentes experiências e por suas raízes culturais específicas, a ocorrência de uma mudança conceitual, em que o conhecimento imediato é totalmente descartado, substituído pelo conhecimento mediato, torna-se difícil, muitas vezes impossível e mesmo indesejável. Essa articulação entre o saber imediato - senso comum - e o saber mediato - conhecimento científico - deve sempre pautar o planejamento do professor, para que não se corra o risco de novamente separar o conhecimento usado para a prova e o conhecimento que será útil no cotidiano. Neste ponto reside a importância de que o aluno participe ativamente do momento do Produzindo, de forma a relacionar os dois conhecimentos, reorganizando-os em uma nova síntese.

A noção de perfil conceitual é mais flexível e permite entender que a evolução das ideias dos alunos em sala de aula pode ocorrer não apenas como uma substituição das ideias alternativas por ideias científicas, mas também como uma evolução de um perfil de concepções, em que as novas ideias adquiridas, mesmo sendo completamente diferentes, passam a conviver com as anteriores e são ambas aceitas como verdadeiras, sendo cada uma delas utilizada em um contexto diferente.

Assim, o aluno pode utilizar a resolução generalizada em sala de aula e apresentada pela fórmula em algumas situações em que ele possua as medidas necessárias ao cálculo da área do triângulo e pode continuar usando sua fórmula alternativa de divisão em quadrados menores e realização de aproximações, em situações de medições de terra, por exemplo, quando ele não tiver condições, nem necessidade, de extrair medidas exatas. Se tiver uma participação ativa na produção deste conhecimento resultante da resolução generalizada, o aluno terá consciência da limitação de seu modelo alternativo e poderá utilizar-se dos dois conhecimentos, de forma crítica, de acordo com sua necessidade. 


\section{Considerações finais}

Conforme percebido através da primeira seção deste escrito, a oferta educacional para as populações do campo foi utilizada durante boa parte de sua trajetória histórica no Brasil como um sistema de reprodução ideológica, que contribuiu para a imposição de um modo de vida e de produção que buscava a realização de interesses econômicos das classes detentoras deste poder de dominação. Pela própria forma como foi ensinado/imposto aos camponeses, no sentido implícito de que sua condição não poderia ser modificada, este povo foi caindo cada vez mais no conformismo e sofrendo suas consequências.

A ascensão dos movimentos sociais do campo ocorrida nos últimos anos contribuiu para que esta realidade pudesse ser modificada. A autoconsciência de um povo dominado e duramente oprimido influencia estes movimentos na busca por novas condições sociais. A educação escolar, como parte do processo de formação humana, é condição importante nesta formação de cidadãos conscientes e libertados. Não obstante, para que a educação possa de fato formar sujeitos sociais críticos, diferentemente do que aconteceu até então, ela deve pautar-se em outras concepções de homem, de mundo e de educação que respeitem o aluno, seus conhecimentos e sua cultura.

Esta necessidade de uma educação diferenciada revela o motivo pelo qual a forma de se ensinar matemática no contexto específico da Educação do Campo não pode se restringir a métodos, a regras e a técnicas preestabelecidas e mecanizadas, como as que são muitas vezes reproduzidas nos livros didáticos. O ensino desta disciplina deve ser tal que ajude a formar cidadãos mais independentes e críticos. Portanto, uma abordagem que considere e utilize o conhecimento do aluno como parte integrante do processo de ensino é imprescindível para que exista de fato, além do ensino, também a aprendizagem. Acredita-se que a Metodologia da Mediação Dialética, se bem planejada e executada, pode contribuir significativamente para que o aluno construa conhecimentos de forma ativa e vinculada aos saberes de sua cultura.

Aulas pautadas na MMD são muito atrativas para o aluno, pois, além de lhe possibilitar tornar-se um agente ativo no seu processo de construção de conhecimentos, exigem-lhe estar o tempo todo retomando os conceitos que já possui e relacioná-los aos que estão sendo trabalhados, tanto em aula quanto nas situações cotidianas, o que reafirma a importância e visualiza a aplicabilidade da matemática escolar no dia a dia, fator que acaba por ajudar a diminuir um problema comum nas aulas de ciências, relacionado à não visualização da utilidade dos conhecimentos trabalhados pelo docente, expresso por comentários como "para que vou utilizar esse conteúdo?” ou "para que estudar isso se nunca vou utilizar para nada?", muito comuns em todas as modalidades de ensino. 
A participação ativa do aluno durante a aula também pode levar ao decréscimo dos problemas de indisciplina enfrentados pelos professores nos diversos níveis educacionais. A necessidade de envolvimento do aluno exige-lhe, obrigatoriamente, dedicar-se às atividades, mantendo-se atento, diminuindo assim os momentos de bagunça e desordem.

É sabido que, no cotidiano da vida do campo, a matemática utilizada nas medições de extensão ou cubagem territorial, nos cálculos de custos, lucros ou prejuízos, entre outros, é uma matemática da experiência vivida que muitas vezes não consegue sequer ser explicada de forma organizada, sendo assim repassada de geração em geração simplesmente através da prática diária. Os sujeitos que fazem parte desta cultura conhecem a aplicação desta matemática e sabem de sua veracidade, sendo assim, se o professor simplesmente desconsiderar este conhecimento do aluno, vai suprimir sua cultura e afirmar ao aprendiz que existem duas matemáticas: aquela da escola - da prova - e a matemática que serve para vida, não havendo assim a geração de uma síntese, já que o aluno não conseguirá por si só estabelecer relações entre estes conhecimentos. Nesse caso, há grande possibilidade de que ele continue a usar e repassar aquele conhecimento do cotidiano que the parece verdadeiro, inutilizando o conhecimento sistematizado em sala de aula.

Como o saber imediato do aluno muitas vezes não é abandonado durante o processo, o professor deve possibilitar ao aluno entender as relações existentes entre esse saber e os saberes cientificamente acumulados, distinguindo quais saberes são apropriados para cada contexto e quais são as suas limitações. Dessa forma, ele continuará convivendo com os dois saberes, sem que ocorra a superação do senso comum pelo conhecimento científico, ou seja, sua participação ativa na formulação do conhecimento sistematizado lhe permitirá um olhar mais crítico frente ao conhecimento imediato, porém o aluno conseguirá estabelecer a relação entre estes dois conhecimentos e os problemas por ele enfrentados na vida campesina, na perspectiva da unidade entre teoria e prática.

Como o desenvolvimento da Metodologia da Mediação Dialética está centrado no trabalho do professor e necessita da sua interferência e planejamento para obter sucesso, destaca-se a necessidade de que ele conheça não somente os conteúdos a serem ensinados mas principalmente os fundamentos dessa concepção e seus desdobramentos na prática pedagógica.

Sabe-se que diversos são os fatores que dificultam a realização de um trabalho pedagógico diferenciado do tradicional no contexto do campo. Como exemplos, podem-se citar a falta de formação específica do professor e da equipe pedagógica para trabalhar neste contexto, a ausência de clareza quanto aos objetivos e especificidades desta modalidade de ensino, a alta rotatividade dos 
professores e a falta de material didático específico para a Educação do Campo. Além disso, mesmo tendo o professor alguma formação sobre o uso destas metodologias alternativas, o planejamento e a execução deste tipo de aula são desafiadores, pois requer o abandono do comodismo da aula tradicional e expositiva, necessitando uma atitude ativa no processo de ensino-aprendizagem.

De fato ocorreram mudanças nos documentos oficiais que regulamentam a Educação do Campo no Brasil, entretanto, no dia a dia das salas de aula muito ainda há para ser feito. É necessário que os trabalhadores da educação, nesse contexto, entendam as especificidades educacionais dessas populações e busquem cada vez mais se aprofundar em estudos e práticas que possam garantir, no cotidiano escolar, um ensino significativo, que possibilite aos estudantes do campo a apropriação dos conhecimentos historicamente acumulados além de uma crítica inserção social.

\section{Referências}

ARNONI, M. E. B. Metodologia da mediação dialética e a operacionalização do método dialético: fundamentos da dialética e da ontologia do ser social como base para discussão da questão metodológica na educação escolar. Disponível em: <http://www. anped.org.br/reunioes/31 ra/1 trabalho/GT04-4971--Int.pdf>. Acesso em: 10 jul. 2011.

ARNONI, M. E. B; OLIVEIRA, E. M; ALMEIDA, J. L. V. Mediação dialética na educação escolar: teoria e prática. São Paulo: Loyola, 2007.

ARROYO, M. G. Educação Básica e movimentos sociais. In: ARROYO, M. G.; FERNANDES, B. M. A educação básica e o movimento social do campo. Brasília: UnB, 1999. p. 15-52.

BRASIL. Lei $\mathrm{n}^{\circ} \mathbf{9 . 3 9 4}$ de 20 de dezembro de 1996. Estabelece as diretrizes e bases da educação nacional. Brasília, 1996.

Secretaria de Educação Fundamental. Parâmetros Curriculares Nacionais: Matemática. Brasília: MEC/SEF, 1997.

. Ministério da Educação. Conselho Nacional de Educação. Diretrizes Operacionais para a Educação Básica nas Escolas do Campo. Brasília, 2002.

. Ministério da Educação. Resolução no . 2, de 28 de Abril de 2008. Disponível em: <http://portal.mec.gov.br/arquivos/pdf/resolucao_2.pdf>. Acesso em: 10 jan. 2012.

CALAZANS, M. J. Questões e contradições da educação rural no Brasil. In: WERTHEIN, J. (Org.). Educação rural no terceiro mundo: experiências e novas alternativas. Rio de Janeiro: Paz e Terra, 1981. p. 161-198.

CESTILLE, J. A. As atividades culturais na proposta educativa dos cursos técnicos de nível médio integrados do MST-PR. 2009. 169 f. Dissertação (Mestrado em Tecnologia) Universidade Tecnológica Federal do Paraná, Curitiba, 2009.

D’AGOSTINI, A. A educação do MST no contexto educacional brasileiro. 2009. 205 f. Tese (Doutorado em Educação) - Faculdade de Educação, Universidade Federal da Bahia, Salvador, 2009. 
MENDES, M. M. A Escola do campo e seu significado: o ponto de vista de professores e professoras da Rede Estadual de Educação do Paraná. 2009. 171 f. Dissertação (Mestrado em Educação) - Universidade Federal do Paraná, Curitiba, 2009.

MONTEIRO, C. E.; LEITÃO, V.; ASSEKER, A. Ensinando matemática em contextos sócio-culturais de educação. Horizontes, Itatiba, v. 27, n. 1, p. 69-78, jan./jun. 2009.

MORTIMER, E. F. Construtivismo, mudança conceitual e ensino de ciências: para onde vamos. Disponível em: <http://www.if.ufrgs.br/public/ensino/N1/2artigo.html>. Acesso em: 15 maio 2011.

MST. Princípios da Educação do MST. Disponível em: <http://intra.vila.com.br/ sites_2002a/urbana/lou/principios.htm>. Acesso em: 20 jan. 2012.

PARANÁ. Secretaria do Estado da Educação. Diretrizes curriculares da educação do campo. Curitiba: SEED-PR, 2006.

SAVELI, E, L. A Proposta Pedagógica do MST para as escolas dos assentamentos - a construção da escola necessária. Publicatio UEPG - Ciências Humanas, Ponta Grossa, v. 8 , n. 1, p. 19-30, 2000.

Recebido em 15/03/2012

Aceito em 10/10/2012 